\title{
Development and Validation of Questionnaire for Physics Learning Self- Efficacy among Ghanaian Senior High Schools
}

\author{
Eric Appiah-Twumasi \\ Orcid: https://orcid.org/0000-0003-2060-3207 \\ Department of Educational Studies \\ Akenten Appiah-Menka University of Skills Training and Entrepreneurial Development, Ghana \\ Collins Agyemang \\ Orcid: https://orcid.org/0000-0003-2873-149X \\ Department of Integrated Science, University of Education, Wineba, Ghana \\ Prof. Yaw Ameyaw \\ Orcid: https://orcid.org/0000-0002-4856-1080 \\ Department of Biology Education, University of Education, Wineba, Ghana \\ Ishmeal Kwasi Anderson, PhD \\ Orcid: https://orcid.org/0000-0002-5445-8282 \\ Department of Physics Education, University of Education, Wineba, Ghana \\ Corresponding Mail: appiatwumasi@gmail.com
}

\begin{abstract}
Copyright resides with the author(s) in terms of the Creative Commons Attribution CC BY-NC 4.0. The users may copy, distribute, transmit and adapt the work, but must recognize the author(s) and the East African Journal of Education and Social Sciences
\end{abstract}

\begin{abstract}
This study focused on developing an instrument for assessing Senior High School students Physics learning self-efficacy beliefs. An instrument known as PLSE was administered on-site and inperson. The PLSE was tested on 290 final year Senior High School Physics students. Prior to this, the initial scale was administered to 60 Senior High School Physics students after validation by seven experts of Science educators. The PCA extracted four factors with loadings ranging from 0.588 to 0.889. The four factors were Physics Practical, Every Application of concepts, High-Order Thinking Skills and Physics Content. The calculated Average Variance Extracted (AVE), and Composite Reliability of the PLSE items were also found to range from 0.540 to 0.718 and 0.823 to 0.927 respectively. The subsequent reliability results showed excellent internal reliability for each of the sub-scales with Corrected Item-total Correlation (CIC) values, ranging between 0.571 and 0.752 . Validity, and reliability assessments revealed accepted threshold cut-off of Average Variance Extracted (AVE), Composite Reliability (CR,) and Cronbach's Alpha coefficient. This paper suggests that the current proposed Physics learning instrument represent a reliable research scale to measure Senior High students Physics learning self-efficacy belief.
\end{abstract}

Keywords: Physics; Self-efficacy; Instrument; Validation Study; Ghana

How to cite: Appiah-Twumasi, E, Agyemang, C., Ameyaw, Y. and Anderson, I. K. (2022). Development and Validation of Questionnaire for Physics Learning Self-Efficacy among Ghanaian Senior High Schools. East African Journal of Education and Social Sciences 3(1), 8-18. Doi: https://doi.org/10.46606/eajess2022v03i01.0141.

\section{Introduction}

Self-efficacy belief describes an individual's ability to organize and accomplish the action required to attain a specific type of performance. In one of his studies, Albert Bandura concluded that an innate mechanism played a considerable role in people's lives. He also stated that, the innate mechanism had not really been defined or systematically observed. The inherent mechanism was then described as

8 East African Journal of Education and Social Sciences (EAJESS) 3(1)8-18 
"self-efficacy belief." Accordingly, self-efficacy belief was defined as the belief someone has in their capabilities, specifically their ability to meet challenges ahead of time and complete a task successfully (Akhtar, 2016). Elizabeth (2020) stated that individuals with high self-efficacy belief tend to be more self-confident in their thinking and reasoning, are highly ambitious, and control their impulses; these are qualities needed for one to succeed.

Anthony and Artino (2012) stated that self-efficacy belief had been a central component in the theories of motivation and learning in a wide-ranging academic and non-academic context. Self-efficacy belief was first proposed as the principal component of a theoretical framework, attempting to explain how behavioral patterns change in the individual (Bandura, 1997). Accordingly, after the publication of Albert Bandura's influential research work titled 'self-Efficacy: Toward a unifying theory of behavioral change,' Bandura (cited in Anthony \& Artino, 2012), many scholars in the field of social and behavioral Sciences have utilized the application of self-efficacy belief to predict and explain a broad range of human functioning and scope. Consequently, self-efficacy belief has been extrapolated far outside the boundaries of phycology, reaching fields as varied as education, health, medicine as well as social and political change. Also, the concept of self-efficacy belief has been used in psychopathology, athletics, business and international affairs (Anthony \& Artino, 2012).

As described by Bandura (1997), self-efficacy belief is different from one individual to the other; they differ under other circumstances, undergo transformation with time, and increase the academic accomplishments of an individual as determined by such factors as physiological, emotional status, mastery experience, vicarious experience, verbal and persuasion. Bandura further claimed that self-efficacy beliefs are predicted by emotional and physiological states such as anxiety, stress, fatigue and mood. Students learn to interpret their physiological arousal as an indicator of their competence by evaluating their performances under differing conditions.

Students' solid emotional reactions to schoolrelated tasks provides the basis for their success or failure. Students' anxiety could also determine their self-efficacy belief. This is because students who experience a feeling of dread when going through a particular school- relate activity each day would likely interpret their anxiety as evidence of lack of skill in that activity. Consequently, increasing students' physical and emotional well-being and reducing their negative emotional states would strengthen their self-efficacy belief.

The concept of self-efficacy belief relates to many other constructs such as self-esteem, Motivation, confidence and others. However, these constructs are not the same as self-efficacy. Some people see self-esteem as self-efficacy belief, but according to Neil (2005), self-esteem is conceptualized as a general or overall feeling of worth or value. Neill added that while self-esteem is focused more on being perfectly accepted by others, self-efficacy belief is more focused on emotion and the capability of meeting challenges ahead of time. It must be emphasized that higher self-esteem can positively promote one's sense of capabilities and abilities, just as high self-efficacy belief can increase one's sense of overall value or worth. Hence, the two constructs are the same.

Similarly, although self-efficacy belief and motivation are deeply related, they are also two distinct constructs. As explained earlier, self-efficacy belief is based on an individual's belief in their own ability to achieve their goals. Motivation, on the other hand, illustrates an individual's desire to succeed. Although these two constructs are related, they are not the same. Meyer (2010) noted that it is true that when an individual gains or maintains selfefficacy belief through past experience of success, however small it is, they generally get a boost and are inspired to continue learning and making progress. For example, students with relatively high self-efficacy belief often have high Motivation and vice versa. It is not a predetermined conclusion that self-efficacious students would have higher motivation, or highly motivated students would be highly productive. Moreover, the connection between self-efficacy and stimulation could also work in the other way to create a sort of success cycle. For instance, Meyer (2010) stated that when students are highly motivated to learn and succeed, they are more likely to achieve anticipated goals, giving them an experience that promotes their overall self-efficacy.

Judgment of self-efficacy belief is generally measured along with three components: magnitude, strength, and generality. According to van der Bijl and Shortridge-Baggett (2002), the selfefficacy belief magnitude scale measures the 
assumed difficult level an individual feels or is required to execute a particular task. Self-efficacy belief magnitude includes adjectives such as easy, moderate and challenging. On the contrary, van der Bijl and Shortridge-Baggett stated that self-efficacy strength refers to the amount of belief and confidence an individual has about successfully executing the task at diverse difficulty levels. Lastly, the generality of self-efficacy denotes the degree to which the expectation is generalized across a situation. An example is how sure a student can apply leant concepts to a new task (Lunenbury, 2011).

Self-efficacy beliefs affect students' mental patterns and emotions that influence any goal-directed actions of students in any situations where students believe they can exercise some control (TschannenMoran, 2009). Therefore, given the critical role of self-efficacy belief in understanding students' behavior, it is helpful to know how students' selfefficacy belief are formed. Bandura's views on selfefficacy belief formation suggest that students can make decisions on their capabilities, based on the verbal encouragement of other experienced people (verbal persuasion) and with the success or failure of other people who serve as models to them (vicarious experiences). (Bandura (1997). Bandura further suggest that perceptions of students' past experiences on teaching and learning activities (mastery experiences) and the level of emotional and physiological condition experienced by students during teaching and learning processes are other sources of developing students' self-efficacy belief.

Pajares (2009) suggested that students develop their self-efficacy belief by judging information from four primary sources. The author further stated that the most significant source is the interpretation of students' previous performance, called the mastery of experience. In addition to understanding the result of their action, the author added that some students could also develop their self-efficacy belief through vicarious means by observing experienced students or teachers executing any activity. Students then create and build their self-efficacy belief due to verbal persuasion from parents, schoolmates, teachers and others. Moreover, students develop self-efficacy belief due to emotional arousal such as anxiety, stress, and mood states (Pajares, 2009). Modified schematic development of the four primary sources of selfefficacy beliefs from Pajares is presented in Figure 1:

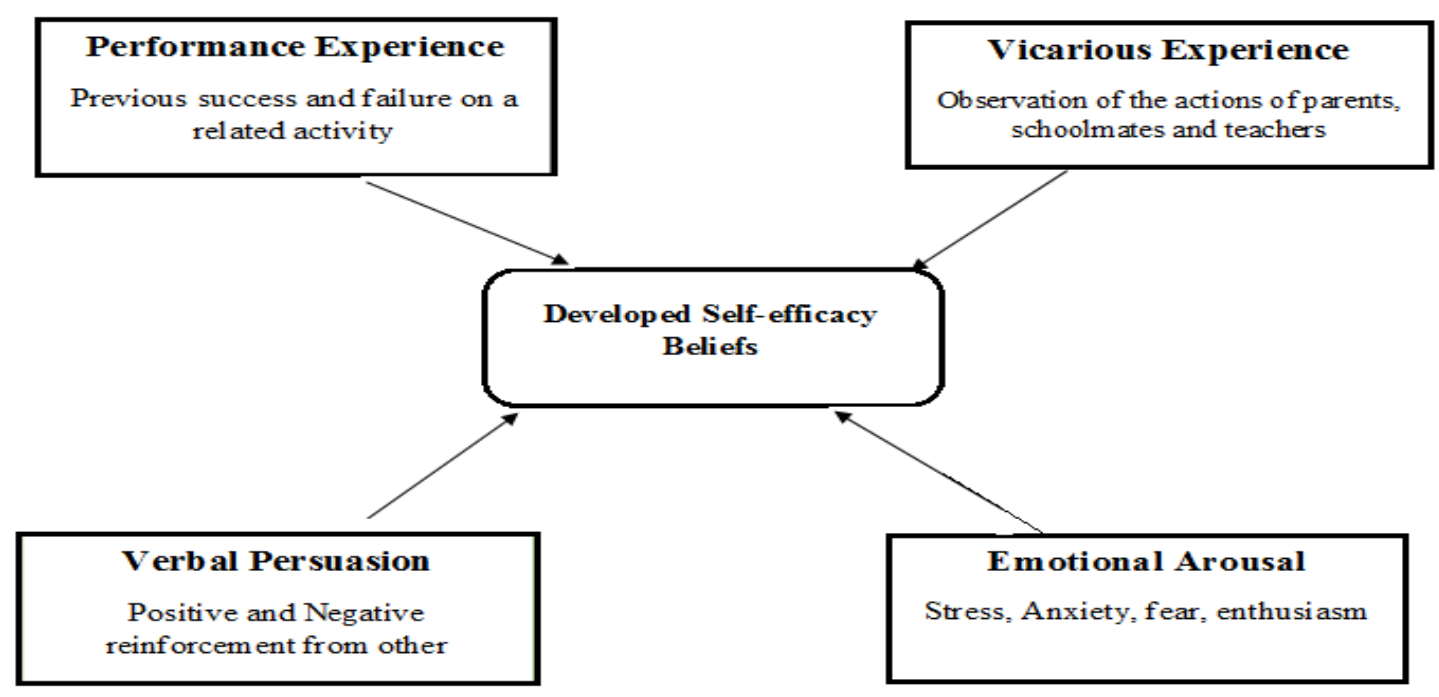

Figure 1: Schematic representation of how self-efficacy is developed

Another important source of developing students' self-efficacy belief is students' personal mastery experiences. Personal mastery information provides the most reliable evidence of whether students could master whatever they need to succeed in a particular academic task (Bandura, cited in Tschannen-Moran, 2009). According to TschnannenMoran (2009), students' personal mastery experiences relating to their past successes build a firm belief of one's self-efficacy, primarily when the said success was achieved with few setbacks or difficulties. However, students' self-efficacy belief may be reduced when success is achieved through total assistance from an efficacious student or teacher after extensive effort or an academic task perceived as easy or unimportant (TscnannenMoran, 2009). 
Consequently, students' mastery of experience has a significant effect on their academic performance in Physics. For example, supposing a student performed well in a previous academic task or examination, the said student is more likely to feel confident and has a high self-efficacy belief expectation to perform well in a similar educational related activity (Redmond, 2016). According to Bandura (1997), this could increase self-motivated persistence to task if the situation is viewed as an achievable challenge (Bandura, 1997). However, supposing a student experienced a failure, such a student is most likely to experience a reduction in their self-efficacy belief with consequential adverse effects on educational achievements.

The vicarious experience source of self-efficacy belief concerns observing another person's actions that one considers challenging. Because learning and mastering learnt concepts lack the absolute definition of adequacy, students must assess their capabilities concerning the performance of other students (Bandura, 1997). The student observing their other colleague can evaluate their capabilities because keeping their colleague provides a measure, which can help the observer set targets for their performance.

According to Tschannen-Moran and McMaster (2009, p.230), "the greater the assumed similarity between the observer and the model, the more persuasive it would be; the belief that one possesses the capabilities to master comparable activities". This implies that when an inefficacious student watches an efficacious student performing any learning task, they are more likely to see that it is manageable. On the contrary, when the observation learning task fails despite solid efforts by the one performing the study, the observer may conclude that the learning task is too challenging to achieve. Consequently, vicarious experience transmits knowledge and teaches inefficacious students practical skills, strategies for managing complex tasks, model behavior, and reveal their thinking about the task at hand.

From the vicarious experience and social learning theory, most learning occurs by observing, modelling and imitating models. Schunk (2008) noted that the primary principle of social learning theory is that students can improve their understanding and retention by observing and modelling the desired behavior, attitudes, reactions of others, and human thought processes. Moreover, the review on vicarious experience shows that most learnings occur in a social environment through vicarious experience(s). Students obtain knowledge, rules, skills, strategies, beliefs, and attitudes by observing others to build their capabilities. This suggests that reciprocal interaction among the students' factors, environmental variables, and behaviors is a significant source of self-efficacy belief.

Self-efficacy is also developed through verbal encouragement and discouragement about individual students' capability to accomplish academic tasks (Redmond, 2010). The verbal encouragement and discouragement involve verbal feedback from other people such as colleagues, teachers, family members, and school administrators that strengthen a student's belief that they possess the capability to attain an anticipated level of academic performance. The implication is that if teachers, colleagues, and others express confidence in an inefficacious student's selfefficacy beliefs or ability to execute a given task, it will promote the student's self-efficacy beliefs (Bandura, 1997).

It must be noted that verbal persuasion may be limited in its quest to develop enduring increased self-efficacy. However, verbal persuasion could reinforce self-change if the positive appraisal promotes more significant effort by a student in developing capacities that subsequently lead to a stronger sense of self-efficacy belief (Redmond, 2016). In schools where inefficacious students often receive verbal persuasion from their colleagues and teachers for executing any academic tasks they are likely to boost their capabilities, promoting improved academic performance. Students may also receive verbal persuasion in the form of specific encouragement from their teachers or colleagues to convince them that they can successfully execute any new teaching and learning task. Verbal persuasion alone may not be a primary source of developing students' self-efficacy belief. However, collaboration with other sources of self-efficacy belief may inspire students to exert more significant effort toward realistic goals to reinforce their capabilities and ability to execute any academic task successfully (Redmond, 2016).

Judging students' capabilities, individual students depend partly on information relative to their physiological and emotional states. Therefore, a student's level of arousal, whether perceived positively, such as expectation or negatively as 
anxiety, could relate to his or herself self-efficacy belief. According to Gregoire (as cited in Sinatra, 2010), students' arousal, such as high heartbeats, increased perspiration, or shaking hands, may affect students, provided the situation is perceived as a challenge or a threat. Therefore, when viewed as a challenge, students' tolerance levels of arousal could improve their performance by focusing attention and effort on the activity. However, students' high levels of arousal viewed as a threat could interfere with the degree to which students could make the best use of their skills and capabilities (Tschnanen-Moran, 2009).

A student's successful completion of an activity creates feelings of accomplishment and excitement, assisting students to develop self-efficacy. Students' exposure to new knowledge or learning activities may induce arousal in the form of interest and curiosity concerning students' academic performance. The situation could cause nervous anticipation for a student, mainly if the student is observed whereas executing the action and afterwards critiquing experienced people. However, when students try out new knowledge in a supportive Physics classroom setting, where encouragement and support are available to such inexperienced students, the anxiety of trying it in the presence of their colleagues and teacher reduces.

Students' self-efficacy beliefs are specific to a particular kind of teaching and learning situation. (Tschannen-Moran, 2009). Also, as a motivational theory, self-efficacy belief affect students' effort and determination, consequently affecting their academic performance, subsequently becoming a new source of self-efficacy belief formation.

Despite the review's emphasis on the importance of self-efficacy beliefs in relation to students' academic success in Physics, no valid national or international questionnaire exists in Ghana to assess Senior High School students' self-efficacy beliefs in learning Physics. Therefore, study's goals were to create a valid and reliable questionnaire to identify and describe the perceived factors influencing senior high school Physics learning self-efficacy beliefs in Ghana.

\section{Methodology}

This section presents the methodology used to conduct the study. It includes such components like research procedure, participants, and selection of item, validity and reliability of the proposed Physics learning self-efficacy belief items.

\section{Procedure}

The proposed Physics learning self-efficacy belief instrument was validated via on-site data collection technique from three Senior High Schools in the Mampong in the Ashanti Region of Ghana. To have a better response rate, the proposed Physics learning self-efficacy belief instrument was administered on-site and in person. This method is very useful in collecting a large amount of data especially when the survey is conducted during a meeting with the respondents. The sample Physics students completed Physics learning self-efficacy instrument three months before their WASSCE examination. The period for data collection was deemed necessary because by that time, most students had completed the curriculum for Senior High School Physics in Ghana.

\section{Participants}

What constitutes an adequate sample size for factor analysis is somewhat complicated. For example, Cattell (1978) recommended three to six participants per item, with a minimum of 250 . Comrey and Lee (1992) subsequently provided a comprehensive rule of thumb as guidance for determining the adequate sample size for many analyses including factor analysis as $100=$ poor, 200 $=$ fair, $300=$ good, $500=$ very good, 1,000 or more $=$ excellent.

As suggested by the literature (Harris, 1985; Comrey \& Lee, 1992; Asamoah-Gyimah \& Doudu, 2007), the sample size of $n>200$ participants from Senior High Schools across Ashanti Mampong Municipality was employed to meet the sample adequacy for factors analysis. Specifically, a total of 290 students selected through randomisation (aged from 17 to 22; $M=$ $18.6, S D=1.31$ ) participated voluntarily in all stages of the development and validation processes.

\section{Selection of Items}

The proposed PLSE instrument composed of four (4) sub-scales designed to assess the SHS students' Physics-learning self-efficacy belief adapted from Suprapto and Chih-Hsiung (2017). PLSE consisted of four sub-scales, including Physics Practical (PP), Everyday Application (EA), High Order Thinking Skill, and Physics Content (PC). (See Table 1.0, and Appendix). The detailed structure of the PLSE is presented in Table 1. 
Table 1: Dimension of the Physics Learning Self-Efficacy Belief Instrument

\begin{tabular}{|c|c|c|}
\hline & Dimension & Description \\
\hline \multirow{4}{*}{ PLSE } & Physics Practical (PP, 5 items). & Measures the SHS students' confidence in their \\
\hline & $\begin{array}{l}\text { Everyday application (EA, } 4 \\
\text { items). }\end{array}$ & $\begin{array}{l}\text { related capabilities to conduct Physics experiments. } \\
\text { Measures the SHS students' confidence in their ability to } \\
\text { apply concepts and skills in their daily life. }\end{array}$ \\
\hline & $\begin{array}{l}\text { High Order Thinking Skills } \\
\text { (HOTS, } 4 \text { items) }\end{array}$ & $\begin{array}{l}\text { Assesses the SHS students' ability to use integrated cognitive } \\
\text { skills, including problem-solving and critical thinking in the } \\
\text { domain of Physics }\end{array}$ \\
\hline & Physics Content (PC,4) & $\begin{array}{l}\text { Assesses the SHS students' confidence in their ability to use } \\
\text { fundamental skills such definitions, formulas, etc. }\end{array}$ \\
\hline
\end{tabular}

As shown in Table 1 and Appendix, the first subscale of PLSE included five (5) questions (LS1-5) and focused on students' Physics Practical. Also, the second sub-scale of the PLSE comprises four (4) items (EA1-4) which address the issue of the competence level of the SHS Physics students' ability to apply Physics concepts in everyday situations. Similarly, the third sub-scale of the PLSE constitutes four items (HOT1-4) which reflect on the SHS students' high-order thinking skills regarding Physics-related concepts. The fourth sub-scale of the PLSE is composed of three items (PC1-3) which assess students' Physics content.

\section{Validity and Reliability Assessment Content Validity Assessment}

A research instrument's validity indicates that the tool accurately measures what it is intended to measure (Middleton, 2020). Content validity, a type of validity, is defined as the extent to which items of a measuring instrument are relevant to and are a representative of the targeted construct for a particular measuring purpose. Therefore, research instruments must have the highest content validity, which would make it easier to obtain valid and reliable evidence intended to be measured. The usual approach for assessing an instrument's content validity is the consultation of experts, which evaluates the instrument. The procedure used is known as expert judgment (Fernández-Gómez et al., 2020).

As stated in the previous sections, all the three research instruments were adapted from previous related studies. However, an instrument developed in a different time, country, or cultural context may not be a valid measure in the group one is studying (Boynton, 2004). The author added that just because a questionnaire has been piloted on a few samples, used in previous studies, or published in a peer-reviewed journal does not mean it is either valid or reliable. Consequently, Boynton recommended that adapted research instruments must be properly validated and standardised.

Consequently, to check the content validities of the research instruments, an expert's judgment was employed. The content validity of the instrument was ensured by six (6) experts, who examined the individual items in each of the instruments and made useful criticisms where necessary. The experts were asked to evaluate the items in the Physics learning self-efficacy belief instrument to assess their accuracy and ability to assess the identified items relative to students' self-efficacy belief in learning Physics. To aid this assessment, Lawshe's (1975) formula was used:

$$
\mathrm{CVR}=\frac{n e-N / 2}{N / 2}
$$

Where CVR = content validity ratio, ne $=$ number of panelists, indicating essential and $\mathrm{N}=$ total number of the panelists.

In equation 1 , greater levels of content validity exist as more significant numbers of panelists agree that a particular item is essential. Lawshe furthered that if up to 7 experts are judging the items, the minimum value of CVR should be kept at 0.970 to ensure that agreement is unlikely to be due to chance. Hence, the accepted value of the CVR was maintained at 0.990 to assess the CVR of the items of the proposed Physics learning self-efficacy instrument (Wilson et al., 2012; Ayre \& Scally, 2014).

\section{Reliability Assessment}

The reliability of the proposed PLSE instrument was conducted using the reliability coefficient (Cronbach's Alpha) for each of the sub-scales of the PLSE instrument. Some authors such as Leech et al. (2011) claim that the reliability of a research instrument can be assessed by measuring a tool's internal consistency and the guaranteed way is the use of Cronbach's alpha for measuring the strength of that consistency. Therefore, to assess the

13 East African Journal of Education and Social Sciences (EAJESS) 3(1)8-18 
reliability of the self-efficacy instrument, the internal consistency reliability method (Cronbach's $\alpha$ ) was used. This method is conventionally defined as an item-level approach because it considers each test item as a separate test. The results of the reliability assessments are presented in Table 2.

Table 2: Internal Consistency of Self-Efficacy of Learning Physics items

\begin{tabular}{lll}
\hline Sub-scale & $\begin{array}{c}\text { Corrected Item-total } \\
\text { Correlation }\end{array}$ & $\alpha$ if Item Deleted* \\
\hline Physics Practical ( PP) & 0.641 & 0.830 \\
Everyday Application (AE) & 0.571 & 0.750 \\
High-Order Thinking Skills (HOTs) & 0.752 & 0.791 \\
Physics Content (PC) & 0.693 & 0.811 \\
\hline
\end{tabular}

Total Items' $\alpha=0.796^{*}$

Table 3: Physics Learning Self-efficacy beliefs Factor Loadings ( $n=290)$

\begin{tabular}{|c|c|c|c|c|c|}
\hline Sub-scale & Items & $M$ & SD & $\begin{array}{l}\text { Factor } \\
\text { Loading }\end{array}$ & Correlation \\
\hline \multirow[t]{5}{*}{ Physics Practical } & LS1 & 2.73 & 1.99 & 0.889 & 0.331 \\
\hline & LS2 & 2.63 & 1.03 & 0.857 & 0.452 \\
\hline & LS3 & 2.52 & 0.98 & 0.885 & 0.311 \\
\hline & LS4 & 2.98 & 1.01 & 0.818 & 0.432 \\
\hline & LS5 & 2.83 & 1.56 & 0.762 & 0.432 \\
\hline \multirow[t]{4}{*}{ Everyday Application } & EA1 & 3.53 & 0.99 & 0.777 & 0.313 \\
\hline & EA2 & 3.67 & 1.25 & 0.783 & 0.422 \\
\hline & EA3 & 3.63 & 1.72 & 0.782 & 0.387 \\
\hline & EA4 & 3.56 & 1.34 & 0.684 & 0.451 \\
\hline \multirow[t]{4}{*}{ High-Order Thinking Skills } & HOT1 & 3.18 & 1.55 & 0.817 & 0.397 \\
\hline & НОТ2 & 3.37 & 1.60 & 0.823 & 0.446 \\
\hline & НОT3 & 2.82 & 1.76 & 0.755 & 0.372 \\
\hline & НОT4 & 3.02 & 1.27 & 0.588 & 0.377 \\
\hline \multirow[t]{5}{*}{ Physics Content } & PC1 & 3.80 & 1.11 & 0.827 & 0.400 \\
\hline & PC2 & 2.69 & 1.37 & 0.777 & 0.393 \\
\hline & PC3 & 3.13 & 1.18 & 0.682 & 0.389 \\
\hline & PC4 & 4.11 & 1.11 & 0.639 & 0.420 \\
\hline & Factor 1 & Factor 2 & Factor3 & Factor 4 & \\
\hline Eigenvalues & 5.880 & 2.930 & 1.751 & 1.230 & \\
\hline Common Variance (\%) & 35.716 & 17.836 & 9.027 & 7.148 & \\
\hline Cumulative Percentage (\%) & 68.995 & & & & \\
\hline KMO & 0.791 & & & & \\
\hline Bartlett's Test of Sphericity & 910.05 & & & & \\
\hline Significant Level & 0.00 & & & & \\
\hline
\end{tabular}

As shown in Table 2, $\alpha=0.796(\geq 0.700)$ is for the self-efficacy of Physics learning items. The Corrected item-total Correlation $(\mathrm{ClC})$, as shown in Table 5 ranged between 0.571 and 0.752 . All items were > 0.300 , and met the minimum threshold.

\section{Factor Analysis}

Upon receiving all the responses from the participants, Principal Component Analysis (PCA) was conducted, involving main components with orthogonal rotation of the Varimax type, with the following assumptions: i) Kaiser-Meyer-Olkin (KMO) sample adequacy test with values higher than $.50 \mathrm{ii}$ )
Bartlett's sphericity test, with $\mathrm{p}<0.05$, factor loading above .30, iii) scree plot of Eigenvalue more significant than one, and iv) $50 \%$ recommendation of cumulative variance (Pontes Júnior et al., cited by Costa et al., 2019).

The correlation matrix revealed many coefficients of 0.3 and above for the PLSE items (See Table 3). Specifically, the results as presented in Table 3.0 shows that the Kaiser-Meyer-Oklin coefficient was found to be 0.791, which far exceeded the recommended value of 0.600 , indicating the sample adequacy requirement for factor analysis was met. 
In addition, Barlett's Test of Sphericity revealed a significant chi-square value $(\chi 2=910.005, \mathrm{df}=289$, $\mathrm{p}<0.05)$, supporting the factorability of the correlation matrix of the Physics Learning Selfefficacy items.

The examination of scree plot revealed that four factors had an Eigenvalue greater than 1. Also, the results as presented in Table 3 show that the four factors altogether captured $68.928 \%$ of the variance, higher than the minimum $50 \%$ threshold recommended by Pontes et al. (cited by Costa et al., 2019). Specifically, factors $1,2,3$ and 4 contributed $35.716 \%, 17.836 \%, 9.027 \%$ and $7.148 \%$, of the common variance with Eigenvalues of 5.880, 2.930, 1.751 and 1.230 respectively were captured. These factor loading values for the seventeen items were in the range of .539 to .875 . Table 4 shows the PCA extracted seventeen items after cross-loadings were deleted and loadings below 0.350 were rejected.
The remaining 17 items had factor loading values range of 0.588 to 0.889 .

Further examination on the scree plot revealed that four factors had an Eigenvalue greater than 1 (See Fig 2). These four factors altogether captured $68.995 \%$ of the variance, higher than the minimum $50.000 \%$ threshold recommended Pontes Júnior et al., cited by Costa et al., (2019). Specifically, factor 1, 2, 3, and 4 contributed 35.772\%, $17.836 \%, 9.027 \%$ and $7.148 \%$, of the common variance with Eigenvalues of 5.880, 2.930, 1.751, and 1.230 respectively, were captured.

To further examine the strength of the PLSE instrument, AVE and CR Composite Reliability were calculated using the factor loading presented in Table 4.0 The results of the AVE and CR are presented in Table 4 . The results as presented in Table 4 revealed that AVE values ranged from 0.540 to 0.718 with corresponding $\mathrm{CR}$ values ranging from 0.823 to 0.927 .

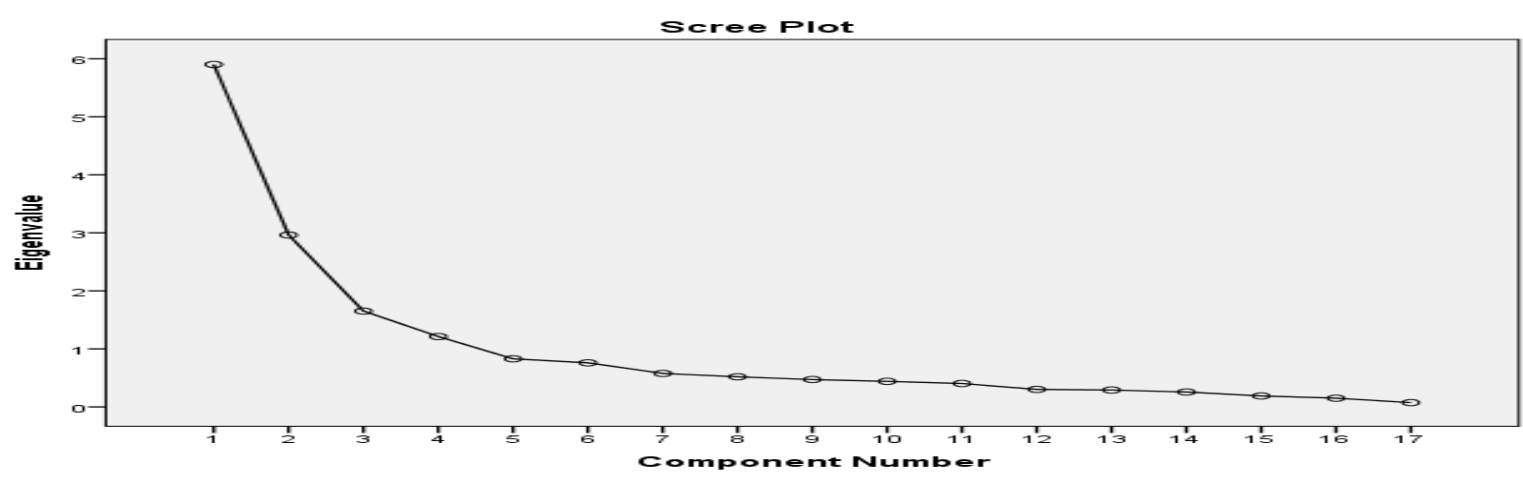

Figure 2: Scree plot of PLSE items

Table 4.0: Calculated AVE and CR of PLSE Instrument

\begin{tabular}{llll}
\hline Dimension & Factor loading & AVE & CR \\
\hline Physics Practical & 0.889 & 0.718 & 0.927 \\
& 0.877 & & \\
& 0.885 & & \\
Everyday Application & 0.818 & & \\
& 0.762 & 0.843 \\
High-Order Thinking Skills & 0.777 & 0.573 & \\
& 0.783 & & \\
Physics Content & 0.782 & & \\
& 0.682 & 0.836 \\
& 0.817 & & \\
& 0.823 & & \\
& 0.755 & & \\
& 0.588 & 0.823
\end{tabular}




\section{Conclusion and Implications \\ Conclusions}

The reliabilities of the instrument were judged sufficient because the alpha value for instrument were well above 0.600 , which is the minimum requirement. Literature (Abel, Buff \& Burr, 2016; Taber, 2018) claim alpha value of 0.900 is considered excellent, 0.800 very good, and 0.700 acceptable and Cristobal et al (2007) contended sub-scale with Corrected Item-Total Correction (CIC) low than the cut of point 0.030 is not acceptable. It could be inferred from the reliability assessments that items of the proposed Physics learning selfefficacy belief instrument sustain a satisfactory level of acceptance of reliability.

Convergent validity is the measure of the level of correlation of multiple indicators of the same construct that are in agreement (Hair, 2014). To establish convergent validity, the factor loading of the indicator, composite reliability (CR) and the average variance extracted (AVE) have to be considered (Hamid et al., 2017). The AVE and CR values should exceed 0.500 so that it is adequate for convergent validity. The CR values as indicated in Table 1.3 shows that all the sub-scales meet the minimum acceptable value of 0.500 . Specifically, mostly all of the AVE values in Table 1.3 exceeded the minimum accepted value of 0.500 .

\section{Implications}

This study attempted to develop and validate a research instrument for the purposes of further studies on Physics students' self-efficacy belief in Ghana. In terms of theoretical implication, the results of factor analysis and reliability test coupled the AVE, and CR have added to the literature with regard to Physics learning self-efficacy belief scale development for Senior High Physics teaching, and learning and self-efficacy related factors.

In terms of practical implication, the study offers suggestion to researchers who wants to identify Senior High School students' Physics learning selfefficacy belief. Researchers can use the validated measures in this study to identify students' Physics learning self-efficacy belief. By doing so, it can improve students self-efficacy belief and enhance their academic performance in Physics. Consequently, the outcome of this study shall guide future research especially in the Physics teaching and learning context in Ghana.

In this study, the validated measures accurately measured the concept of Physics learning self- efficacy belief in Ghanaian Senior High Physics teaching and learning. The reliability of the proposed instrument has been found consistent with recommended cut-off values and, thus, indicates the homogeneity of the items in the proposed Physics learning self-efficacy belief instrument for Senior High School students. Hence, the proposed validated Physics learning self-efficacy instrument can be used by future researchers who want to measure Physics students' self-efficacy belief in learning Physics.

\section{References}

Abel, J., Buff, C., \& Burr, S. (2016). Social media and the fear of missing out: scale development and assessment. Journal of Business \& Economics Research (JBER), 14 (1), 33-44.

Akhtar, I. (2016). Research design. Retrieved from https://www.researchgate.net/public ation/30 8915548

Anthony, R., \& Artino, J. (2012). Academic selfefficacy: From educational theory to instructional practice. Perspective Medical Education, 1 (2), 76-85.

Asamoah-Gyimah, K., \& Doudu, F. (2007). Introduction to Research Methods in Education. Winneba: UEW, IEDE.

Bandura, A. (1997). Social fundations of thought and action : A social cognitive thoery. Englewood Cliffs, NJ: Prentice- Hall.

Boynton, P. M. (2004, May 29). Selecting, designing and developing your questionnaire. Retrieved from https://www.ncbi.nl m.nih.gov/pmc/articles /PMC420179/

Cattell, R. (1978). The Scientific Use of Factor Analysis in Behavioral and Life Sciences. New York: Plenum.

Comrey, A. L. \& Lee, H. B. (1992). A first course in factor analysis (2nd ed.). Hillsdale, NJ: Lawrence Erlbaum.

Costa, R. Z., Medina-Papst, J. S., de Santo, L., \& Marques, I. (2019). Content validity, reliability and construct validity of a checklist for dive roll evaluation. Journal of Physics Education, 30 (e3054), 1-10.

Cristobal, E., Flavian, C., \& Guinaliu, M. (2007). Perceived e-service quality (PeSQ): measurement validation and effects on 
consumer satisfaction and web site loyalty. Management Service Quality, 17 (3), 317340.

Elizabeth, T. (2020, January 2). Personality: Conscientiousness and agreeableness. Retrieved from https://www.retorio .com/ blog/ conscientiousness-and-agree ableness.

Fernández-Gómez, E., Martín-Salvador, A., LuqueVara, T., Sanchez-Ojeda, M. A., NavarroPrado, S., \& Enrique-Miron, C. (2020). Content validation through expert judgement of an instrument on the nutritional knowledge, beliefs, and habits of pregnant women. Nutrients, 12 (1136), 113.

Hair, J., Black, W., Babin, .., \& Anderson, R. (2014). Multivariate data analysis (7th ed.). Upper Saddle River, N.J: Prentice Hall.

Hamid, M. R., Sami, W., \& Sidek, M. H. (2017). Discriminant validity assessment: Use of Fornell \& Larcker criterion versus HTMT Criterion. Journal of Physics: Conference Series, 890 (2017) 01263.

Lawshe, C. H. (1975). A quantitative approach to content validity. Personnel Psychology, 28, 563- 575 .

Leech, N., Barrett, K., Morgan, G., \& Leech, N. (2011). IBM SPSS for intermediate statistics. New York: Routledge.

Lunenbury, F. C. (2011). Self-efficacy in the workplace: Implications for motivation and performance. International Journal of Management, Business and Administration, 14 (1), 1-6.

Meyer, E. J. (2010). Gender and sexual diversity in schools. New York, NY: Springer.

Middleton, F. (2020, June 26). Reliability vs validity: what's the difference? Retrieved from https://www.scribbr.com/methodology/reli abilityvsvalidity/\#: :text=Reliabilidity\%20an d\%2 Ovalidity\%20are\%20concepts,the\%2 0accurately\%20ofa\%20measure.

Neil, J. (2005, March 17). Definitions of the various self-constructs: Self-efficacy, self-confidence and self-concept. Retrieved from http://www. wilderdom. com/ self/.

Pajares, F. (2009). Towards a posture of academic motivation: The role of self-efficacy beliefs. In R. Gilman, E. S. Huebner, \& M. J. Furlong(Eds), Handbook of positive psychology in schools (pp. 149-160). New York: Taylor and Francis.

Redmond, B. F. (2016, February). 7 self-efficacy and social learning theories. Retrieved from wikispace.psu.edu/display/PSYCH484/7.+Sel f-Efficacy+and+ Socail+Cognitive+Theories.

Schunk, D. H. (2008). Self-efficacy and academic motivation. Educational Psychology, 26, 207-231.

Sinatra, G. M. (2010, June 8). The warning in conceptual change research: The legacy of Pual R. Pintrich. Retrieved from http://doi.org/10. 1207/s 15326985 ep4002_5.

Suprapto, N., \& Chih-Hsiung, K. (2017). Conception of learning physics and self-efficacy among Indonesian university students. Journal of Baltic Education, 16 (1), 7-19.

Tschannen-Moran, M., \& McMaster, P. (2009). Sources of self-efficacy for professional development format and their relationship to self-efficacy and implementation of a new teachinng stratagy. The Elementary School Journal, 110 (2), 229-245.

Tschnannen-Moran, M. (2009). Sources of selfefficacy: Four professional development formats and their relationship to selfefficacy and implementation of a new teaching strategy. The Elementary Journal, $10(2), 228-245$.

van der Bijl, J. J., \& Shortridge-Baggett, L. M. (2002). The theory and measurement of the selfefficacy construct. In E. A. Lentz, \& L. M. Shortridge-Baggett(Eds), Self-efficacy in nursing: Rsearch and measurement perspectives (pp. 9-28). New York: Springer.

Wilson, F. R., Pan, W., \& Schumsky, D. A. (2012). Recalculation of the critical values for Lawshe's content validity ratio. Measurement and Evaluation in Counseling and Development, 45 (3), 197-210. 


\section{APPENDIX \\ PHYSICS LEARNING SELF-EFFICACY QUESTIONNAIRE (PLSE)}

Here are a number of self-efficacy beliefs items which explores SHS student Self-Efficacy beliefs in learning Physics. Please give your opinion on the following on the items by circling to indicate your response. The options are: $S A=S$ trongly Agree, $A=A g r e e, N=$ Neutral, $D=$ Disagree $S D=$ Strongly Disagree

\begin{tabular}{|c|c|c|c|c|c|c|c|}
\hline Dimension & $\mathrm{S} / \mathrm{N}$ & Item & SA & A & $\mathrm{N}$ & D & SD \\
\hline \multirow[t]{5}{*}{$\begin{array}{l}\text { Physics } \\
\text { Practical }\end{array}$} & PP1 & $\begin{array}{l}\text { I know how to use equipment in Physics } \\
\text { laboratory. }\end{array}$ & SA & A & $\mathrm{N}$ & $D$ & SD \\
\hline & PP2 & $\begin{array}{l}\text { I know how to set-up equipment for my Physics } \\
\text { practical. }\end{array}$ & SA & $A$ & $\mathrm{~N}$ & $D$ & SD \\
\hline & PP3 & $\begin{array}{l}\text { I know how to collect data during Physics } \\
\text { practical. }\end{array}$ & SA & $A$ & $\mathrm{~N}$ & $D$ & SD \\
\hline & PP4 & $\begin{array}{l}\text { I am confident that I can set-up my WASSCE test } \\
\text { of practical examination. }\end{array}$ & SA & $A$ & $\mathrm{~N}$ & $D$ & SD \\
\hline & PP5 & $\begin{array}{l}\text { I know how to carry out experimental } \\
\text { procedures in the Physics laboratory. }\end{array}$ & SA & $A$ & $\mathrm{~N}$ & $D$ & SD \\
\hline \multirow[t]{4}{*}{$\begin{array}{l}\text { Everyday } \\
\text { Application }\end{array}$} & EA1 & $\begin{array}{l}\text { I am able to use scientific methods to solve } \\
\text { problems in everyday life. }\end{array}$ & SA & $A$ & $\mathrm{~N}$ & $D$ & SD \\
\hline & EA2 & $\begin{array}{l}\text { I am able to apply what I have learned in school } \\
\text { Physics to daily life. }\end{array}$ & SA & A & $\mathrm{N}$ & D & SD \\
\hline & EA3 & $\begin{array}{l}\text { I am able to propose solutions to everyday } \\
\text { problems using Physics. }\end{array}$ & SA & A & $\mathrm{N}$ & $\mathrm{D}$ & SD \\
\hline & EA4 & $\begin{array}{l}\text { I can understand and interpret social issues } \\
\text { related to Physics in a scientific manner. }\end{array}$ & SA & $A$ & $\mathrm{~N}$ & $\mathrm{D}$ & SD \\
\hline \multirow[t]{4}{*}{$\begin{array}{l}\text { High-Order } \\
\text { Thinking Skill }\end{array}$} & HOT1 & $\begin{array}{l}\text { I am able to make systematically observations } \\
\text { and inquiry based on a specific Physics concept. }\end{array}$ & SA & A & $\mathrm{N}$ & D & SD \\
\hline & НОT2 & $\begin{array}{l}\text { I can explore a Physics phenomenon, observe its } \\
\text { changing process and assign reason(s) to it. }\end{array}$ & SA & $A$ & $\mathrm{~N}$ & D & SD \\
\hline & НОТЗ & $\begin{array}{l}\text { When I come across a Physics problem, I will } \\
\text { actively think over it first and devise a strategy to } \\
\text { solve it. }\end{array}$ & SA & $A$ & $\mathrm{~N}$ & D & SD \\
\hline & HOT4 & $\begin{array}{l}\text { I am able to propose many appropriate solutions } \\
\text { to solve a Physics problem. }\end{array}$ & SA & $A$ & $\mathrm{~N}$ & D & SD \\
\hline \multirow[t]{4}{*}{$\begin{array}{l}\text { Physics } \\
\text { Content }\end{array}$} & PC1 & $\begin{array}{l}\text { I can select an appropriate Physics formula to } \\
\text { solve a Physics problem. }\end{array}$ & SA & $A$ & $\mathrm{~N}$ & $\mathrm{D}$ & SD \\
\hline & PC2 & $\begin{array}{l}\text { I can transfer the knowledge learned in Physics } \\
\text { to different Physics concept and establish their } \\
\text { relationship between them. }\end{array}$ & SA & $A$ & $\mathrm{~N}$ & $\mathrm{D}$ & SD \\
\hline & PC3 & $\begin{array}{l}\text { I know the definitions of Physics concepts very } \\
\text { well. }\end{array}$ & SA & $A$ & $\mathrm{~N}$ & $D$ & SD \\
\hline & PC4 & $\begin{array}{l}\text { I feel confident when I am explaining Physics } \\
\text { concepts to my classmates. }\end{array}$ & SA & A & $\mathrm{N}$ & $D$ & SD \\
\hline
\end{tabular}

